\title{
POSSIBILIDADE DE APLICAÇÃO DA TÉCNICA DE CONSTELAÇÕES FAMILIARES E DA MEDIAÇÃO NAS VARAS ESPECIALIZADAS DA MULHER E DA VIOLÊNCIA DOMÉSTICA FRENTE À RESOLUÇÃO CNJ N 125/2010
}

\author{
Artenira da Silva e Silva*1 \\ Gabriella Sousa da Silva Barbosa**2
}

\section{Resumo}

A promulgação da Lei Maria da Penha marca a retirada das demandas referentes à violência doméstica do paradigma conciliatório dos juizados especiais em que os delitos por ela albergados até então eram julgados. Por outro lado, a Resolução do Conselho Nacional de Justiça $n^{\circ} 125 / 2010$ privilegia a utilização dos chamados meios alternativos para resolução de conflitos, iniciando uma nova perspectiva, a do privilégio à autocomposição. Por meio de uma revisão bibliográfica, investigou-se se a utilização da técnica da constelação familiar e ou da Mediação seria cabível como técnicas a serem utilizadas nas demandas referentes à violência doméstica.

Palavras-chave: Violência doméstica; Técnica da Constelação Familiar; Mediação; Meios alternativos para resolução de conflitos; Autonomia.

\section{POSSIBILITY OF THE APPLICATION OF FAMILY CONSTELLATION TECHNIQUES AND MEDIATION IN THE SPECIALIZED SEASONS OF WOMEN AND DOMESTIC VIOLENCE IN FRONT OF RESOLUTION CNJ Nº 125/2010}

\begin{abstract}
The promulgation of the Maria da Penha's Law marks the withdrawal of the demands related to domestic violence from the conciliatory paradigm of the special courts in which the crimes it hosted until then were judged. On the other hand, the Resolution $n^{\circ}$. 125/2010 from National Council of Justice favor the use of the called alternative means for resolving conflicts, starting a new perspective, that privilege the self-composition. In this sense, through a bibliographical review, whether the use of the family constellation technique and mediation would be appropriate techniques to be used in the demands related to domestic violence.
\end{abstract}

Keywords: Domestic Violence; Family Constellation Technique; Mediation; Alternative Means for resolving conflicts; Autonomy.

\footnotetext{
1 *Pós-doutora em Psicologia e Educação pela Universidade do Porto. Doutora em Saúde Coletiva pela Universidade Federal da Bahia. Mestre em Saúde e Ambiente pela Universidade Federal do Maranhão, Graduada em Psicologia pela Pontifícia Universidade Católica de São Paulo. Docente e pesquisadora do Departamento de Saúde Pública e do Mestrado em Direito e Instituições do Sistema de Justiça da Universidade Federal do Maranhão. Coordenadora de linha de pesquisa do Observatório Ibero Americano de Saúde e Cidadania e coordenadora do Observatorium de Segurança Pública (PPGDIRUFMA/CECGP). Psicóloga Clínica e Forense. Email: artenirassilva@ hotmail.com

2 **Mestranda do Programa de Pós-Graduação em Direito e Instituições do Sistema de Justiça da Universidade Federal do Maranhão - UFMA. Graduada em Direito pela Unidade de Ensino Superior Dom Bosco - UNDB. Advogada. Pesquisadora CAPES. E-mail: gssbarbosa@gmail.com
} 


\section{INTRODUÇÃO}

A Técnica das Constelações Familiares fora criada no fim do século XX, objetivando, de modo fenomenológico e sistêmico, a representação de conflitos familiares e consequente percepção pelos pacientes, denominados constelados, das dificuldades emocionais e origem dos conflitos existentes em seus casos concretos. (CÉSPEDES, 2017, p.12)

Esta técnica, criada pelo Alemão Bert Helling, passou a ser utilizada em diversas áreas, servindo, de um modo geral, para ampliar o diálogo entre os sujeitos que possuem restrições de caráter relacional em função de relações familiares mal elaboradas emocionalmente, restringindo as suas formas de interagir nos seus ambientes de trabalho. No Direito, têm-se por foco, quando se faz uso da referida técnica, o aprimoramento do diálogo entre as partes litigantes, com enfoque especial nas demandas de Direito de Família, visando reestabelecer um contato mais saudável entre os litigantes (CNJ, 2014, p.1).

Desse modo, a Técnica das Constelações Familiares vem sendo utilizada, a partir dos anos 2000, no Direito brasileiro, como uma fase preparatória à utilização dos meios consensuais de resolução de conflitos, trabalhando as partes para que, através da percepção dos problemas raiz daquela demanda trazida a juízo, estejam mais propícias a uma concreta resolução de seu problema judicializado. (CÉSPEDES, 2017, p. 37)

Considera-se, em princípio, que nem todas as demandas são passíveis de serem melhor resolvidas ou de terem seu potencial de conflito minimizado através da utilização de meios consensuais para resolução de seus conflitos. A fim de reafirmar este entendimento inicial, uma das maiores problematizações quando da não existência da Lei Maria da Penha era a condução dos crimes com pena de até dois anos aos juizados especiais. Nestes locais mantinha-se um espírito conciliatório e a presença das transações penais, o que representava, no plano prático, a impunidade do agressor. (BARSTED, 2011, p. 27)

É nesse sentido e tomando-se a utilização da Técnica das Constelações Familiares como proposta precedente ao uso dos meios consensuais de resolução de conflitos, que se analisa se o uso desta técnica pode ou não facilitar a percepção e compreensão de vítimas e agressores dos diversos fatores psicosócioculturais introjetados que se fazem presentes nas demandas referentes à violência doméstica e familiar contra mulheres.

Por sua vez, a Mediação caracteriza-se por um método pacífico de resolução ou administração de conflitos. De um modo geral, este método, conjuntamente à negociação e à 
conciliação, integra o grupo dos ditos meios mais adequados ou alternativos de resolução de conflitos autocompositivos, nos quais as partes tentam encontrar entre si a solução de suas demandas - diferenciando-se, portanto, da arbitragem, também um meio alternativo, mas embasado pela heterocomposição, na qual um terceiro nomeado de árbitro torna-se responsável pela decisão que obrigará as partes. (GRINNOVER, 2009, p. 2)

A mediação, através da proposta de uma resolução de demandas não adversarial, acaba por apresentar uma lógica diferenciada daquela encontrada no uso comum do Poder Judiciário. Diferentemente da racionalização ganhador-perdedor presente nas varas de justiça, na qual se estimula o antagonismo e a rivalidade entre as partes, a técnica tem o escopo de fazer autor e réu voltarem a dialogar, dando-lhes papel de protagonistas para resolução daquele problema judicializado. (MUSZKAT, 2003, p. 34)

É desse modo que se pode afirmar que a mediação representa o triunfo da cultura do pacto sobre a cultura do confronto (MUSZKAT, 2003, p.4). Busca-se fazer com que os envolvidos compreendam as circunstâncias que motivaram aquela ação judicial, assim como, diante da responsabilização das partes e minimização dos danos gerados pela solução consensual, a obtenção de escolhas mais duradouras (FONSECA; SAUÁIA, 2014, p. 173).

É nesse sentido que a utilização da técnica de mediação em conflitos familiares ganha destaque, uma vez que, saindo da lógica ganhador-perdedor, impraticável nas demandas envolvendo vínculos de paternalidade e conjugalidade, permite que as partes trabalhem os conflitos raiz, alcançando consensualmente a solução desejada e conseguindo cumpri-la, de modo a diminuir futuros acessos ao Judiciário que reflitam resíduos daquelas demandas anteriores mal resolvidas.

Para tanto, além da realização da revisão de literatura através da pesquisa bibliográfica, a fim de aprofundar os conceitos explorados ao longo do presente trabalho, como procedimento metodológico, analisaram-se os resultados de dois estudos de caso. O primeiro referente à introdução da Técnica das Constelações Familiares no Brasil pelo magistrado Sami Storch, na comarca de Castro Alves no interior da Bahia e o segundo abordando os impactos da implantação de um Núcleo Experimental de Mediação na Delegacia Especial de Atendimento à Mulher - DEAM no Estado de Sergipe.

\section{1- UTILIZAÇÃo dA TÉCNICA DA CONSTELAÇÃo FAMILIAR NO DIREITO BRASILEIRO}


A Técnica da Constelação Familiar fora desenvolvida pelo filósofo, psicoterapeuta e teólogo alemão Bert Hellinger na década de 1980. Concebe-se que o estudioso não criou efetivamente a técnica, mas sim transformou e uniu outras anteriormente existentes em saberes de comunidades tribais, teorias e métodos de outros autores da filosofia, teologia, psicologia e psicanálise, extraindo princípios que norteariam a nova propositura de abordagem, revestindoa de um caráter mais científico. (CÉSPEDES, 2017, p.12)

Através do estudo da dinâmica de grupo, do psicodrama do psiquiatra Jacob Moreno, da Terapia Contextual de Ivan Boszormenyi-Nagy, da Técnica da Família Simulada de Virginia Satir, da terapia primal, da análise transacional e de diversos métodos hipnoterapêuticos, desenvolveu a Constelação Familiar Sistêmica. (ALMEIDA, 2008, p.1)

A Técnica das Constelações Familiares de Helling pode ser considerada uma abordagem da Terapia Sistêmica Fenomenológica (CARVALHO, 2012, p. 43). Esta última fora criada por Edmund Husserl, melhor descrita em sua obra Investigações Lógicas de 1901, quando substituiu a expressão "psicologia descritiva" que utilizava até então (ZILES, 2007, p. 4). A teoria de Husserl atingiu seu momento marcante na década de 1920, quando surgiram escolas que acabaram por utilizar alguns aspectos de suas concepções para as construções teóricas que intentavam, como a ontologia existencial de Heidegger e a ética dos valores de Max Scheler. (ZILES, 2007, p.1)

A fenomenologia hursseniana possui o objetivo inicial de "[...] satisfazer à objetividade do conhecimento, seja ele ideal ou real, e à subjetividade do cognoscente" (ZILES, 2007, p.3) e, para tanto, tem por meta a construção de uma ciência da essência do conhecimento ou doutrina universal das essências (SILVA; LOPES; DINIZ, 2006, p. 255).

O termo fenomenologia significa estudo dos fenômenos, daquilo que aparece à consciência, daquilo que é dado, buscando explorá-lo. A própria coisa que se percebe, em que se pensa, de que se fala, tanto sobre o laço que une o fenômeno com o ser de que é fenômeno, como sobre o laço que o une com o Eu para quem é fenômeno. (SILVA; LOPES; DINIZ, 2006, p. 255)

É nesse sentido que as observações de Bert Helling levaram-no a conceber uma técnica cujo trabalho consiste na transformação dos vínculos não perceptíveis conscientemente dentro de uma família ou um sistema de vínculos invisibilizados, por meio de uma representação espacial (ALMEIDA, 2008, p. 1). Ademais, concebe-se a existência de um "movimento da alma" que interligaria os participantes da terapia por meio da representação, 
uma vez que haveria um equilíbrio do grupo, portanto sistêmico. (CHIQUETTI; CRUZ, 2016, p. 11).

\begin{abstract}
Nas constelações familiares, praticadas em grupo ou na terapia individual, diversos elementos da psicoterapia se desenvolvem e convergem num instrumental representativo, capaz de trazer à luz os processos anímicos, vivenciá-los e reduzi-los ao núcleo essencial que permite soluções. Ao mesmo tempo, esse instrumental leva a profundas experiências e descobertas humanas, que apontam para amplos domínios coletivos e espirituais, ultrapassando as fronteiras, por vezes estreitas, da psicoterapia. A solução de problemas psíquicos associa-se à descoberta das ligações da alma, em conexão com as ocorrências e os destinos familiares e com os grupos e os contextos maiores que os abrangem. (SCHNEIDER, 2007, p.9)
\end{abstract}

A fim de alcançar os objetivos propostos, a técnica é regida por três princípios básicos, denominados ordens do amor e que representam as necessidades essenciais para a manutenção sadia dos relacionamentos humanos e da constituição dos sistemas, ou seja, de grupos sociais. São elas: o pertencimento ou vinculação a um grupo; a necessidade de se estabelecer uma ordem, a importância de se estruturar o sistema em relação ao tempo de ingresso no mesmo, à função ou à hierarquia entre os membros; e a manutenção entre o dar e o receber (HELLINGER, 2015, p. 25)

Para o autor, tais ordens do amor não são criadas, mas descobertas, existindo mesmo diante da incompreensão dos membros, daí advindo, portanto, a possibilidade de, através da representação, fazê-las visíveis aos indivíduos que buscam a terapia. O princípio do pertencimento pondera que nenhum membro do grupo pode ser excluído do mesmo por nenhum motivo. Quanto à hierarquia, têm-se não só que se deve respeitar a origem cronológica, quando pais devem preceder aos filhos, por exemplo, como também a hierarquia pelo progresso, na qual o novo sistema deve prevalecer em relação ao anterior. Por fim, o dar e receber/tomar salienta a necessidade de um equilíbrio entre os membros de um sistema, não só pela doação um filho, eterno devedor dos pais, mas os filhos também dão continuidade à família ou lhes doam uma realização para a humanidade, por exemplo -, como pela compensação de ações nos relacionamentos conjugais. (CHIQUETTI; CRUZ, 2016, p. 13)

\footnotetext{
As culpas e as consequências retornam às pessoas a que pertencem, e começa a reinar a compensação por meio do bem, substituindo a necessidade sinistra de equilibrar por meio do funesto, que gera o mal a partir do mal. O sucesso acontece quando os mais novos aceitam o que receberam dos mais velhos. Os excluídos recuperam seu direito de ser acolhidos e nos abençoam ao invés de nos amedrontarem. Quando lhes damos um lugar em nossa alma, ficamos em paz com eles. A partir do momento que estamos de posse de todos os que nos pertencem, de todos os que fazem parte do nosso sistema familiar, sentimo-nos inteiros e plenos no amor que pode fluir e crescer. Aquilo que se coloca a caminho, sem nenhuma intenção,
} 
sem medo e sem vontade de ajudar alguém de qualquer maneira. Por meio do trabalho com os representantes eles se movimentam e encontram soluções que estão além da influência do constelador ou do terapeuta. (CARVALHO, 2012, p. 43)

É regida pelos referidos princípios que a terapia se desenvolve tanto de modo individual, com a presença do constelado - paciente - e do constelador - terapeuta - por meio da utilização de bonecos ou qualquer objeto que sirva para representar os membros do sistema, ou mesmo em grupo, quando um terceiro é chamado a atuar como um membro do sistema do paciente, percebendo-se as sensações e movimentos que, até então estavam ocultos naquele sistema representado. (CÉSPEDES, 2017, p. 19)

\begin{abstract}
O que há de extraordinário nas constelações familiares é primeiramente o próprio método. É singular e fascinante observar, quando um cliente coloca em cena pessoas estranhas para representar seus familiares em suas relações recíprocas, como essas pessoas, sem prévias informações, vivenciam sentimentos e usam palavras semelhantes às deles e, eventualmente, até mesmo reproduzem os seus sintomas. Quando os representantes são instados a expressar em movimentos o que sentem, eles frequentemente exprimem uma dinâmica da alma que revela destinos ocultos, que o próprio cliente desconhecia. Algumas vezes, o que os representantes sentiram só fica claro para o cliente depois que ele se informa com sua família. (SCHNEIDER, 2007, p. 10)
\end{abstract}

No Brasil, a utilização da terapia das constelações familiares como método auxiliar à prática forense fora iniciada em 2006, com a atuação do magistrado Sami Storch, titular da comarca de Castro Alves, interior da Bahia. Ressignificando o termo Direito Sistêmico, o juiz propõe a utilização de um método sistêmico-fenomenológico de solução de conflitos, a atuar na origem do problema. (CÉSPEDES, 2017, p. 37)

Durante a introdução da terapia na Vara de Família do município, faziam-se três reuniões - terapia em grupo - com três casos constelados por dia. Segundo dados de 2012 e 2013, os resultados obtidos nas audiências, em sua maioria de casos de guarda, alimentos ou divórcio mostraram-se positivos. $91 \%$ de conciliações em audiências nas quais uma das partes havia participado das constelações e $100 \%$ de acordos naquelas em que ambas as partes foram submetidas à terapia proposta. (CNJ, 2014, p.1)

Storch na sua trajetória como jurista, primeiro na advocacia e depois na magistratura, percebeu que os relacionamentos humanos nem sempre se orientam pelas leis positivadas, que muitos dos conflitos vivenciados entre grupos ou entre indivíduos têm origem em questões mais profundas do que os fatos trazidos aos autos de um processo judicial, percebeu ainda que na presença de uma complexidade maior do que o que pode ser aparentemente percebido, os ditames das leis ou da decisão judicial não sanam a questão trazida ao direito. Em sua experiência na magistratura observou que mesmo quando uma ou ambas as partes se sentiam aliviadas com o 
proferir da sentença, a questão permanecia, vindo posteriormente exigir sua resolução, retirando a tranquilidade $\mathrm{e}$, muitas vezes, trazendo novamente à esfera jurídica os envolvidos. (CÉSPEDES, 2017, p. 37)

Diante da proposta trazida pelo magistrado ao direito pátrio o Poder Judiciário tem absorvido a técnica para maximizar a possibilidade de se obter a resolução mais adequada a conflitos que demonstrem intensa complexidade. Segundo dados do Conselho Nacional de Justiça-CNJ (2016, p.1) ao menos 11 estados já utilizam esta técnica, a exemplo de São Paulo, Rondônia, Pará e Alagoas. No Distrito Federal, a prática autorizada pelo juiz titular de Direito da Vara da Infância e Juventude - VIJ, Renato Scussel, em uma unidade de acolhimento, Lar São José no ano de 2015, sob influência da pesquisa acadêmica da voluntária Adhara Campos, suscitou a criação do Projeto Constelar e Conciliar. (CNJ, 2016, p.1)

É diante dos resultados obtidos nas varas de família com a utilização da técnica em questão e do histórico negativo da prática de conciliações frente aos contextos de violência doméstica e ou intrafamiliar contra a mulher, antes da vigência da Lei Maria da Penha, $\mathrm{n}^{\mathrm{o}}$ 11.340/2006, que se pretende analisar no presente estudo a pertinência ou não da aplicação da Técnica das Constelações Familiares e da Mediação também às demandas de violência doméstica.

\section{2- DA APLICAÇÃO DA MEDIAÇÃO EM DEMANDAS DE VIOLÊNCIA DOMÉSTICA}

A criação da Lei $n^{\circ}$ 11.340/2006, denominada Lei Maria da Penha, é reconhecida como um marco para a proteção de mulheres em casos de violência doméstica no país. Instituída por influência de uma condenação no caso Maria da Penha Maia Fernandes da Corte Interamericana de Direitos Humanos ao Estado Brasileiro, no ano de 2001, por omissão e negligência no enfrentamento das questões relativas à violência doméstica (DIAS, 2007, p. 14), em específico por descumprimento ao artigo $7^{\circ}$ da Convenção de Belém do Pará, assim como aos artigos $1^{\circ}, 8^{\circ}$ e 25 da Convenção Americana de Direitos Humanos, têm-se que a lei reflete um longo processo de luta dos movimentos feministas e de organizações de mulheres da sociedade civil ao longo de décadas no país (CALAZANS; CORTES, 2011, p. 56).

A luta pelo direito a uma vida sem violência, que possibilitou a aprovação da Lei Maria da Penha, em 2006, é um caso exemplar de exercício de uma cidadania ativa expressa no discurso e na atuação das feministas no espaço público. Sintetiza, também, a longa interlocução das feministas com os poderes legislativo e executivo e 
aponta para a necessidade de investimentos contínuos no diálogo com o poder judiciário e com as demais instituições da justiça. (BARSTED, 2011, p. 15)

Pautando-se por uma base principiológica inspirada tanto no direito internacional, quanto no respeito ao constitucionalismo pátrio, há que se conceber a Lei Maria da Penha, $\mathrm{n}^{\circ}$ 11.340/2006, como um avançado instrumento de proteção das mulheres em situação de violência doméstica e familiar. (LAVIGNE; PERLINGEIRO, 2011, p. 290)

\begin{abstract}
Enquanto um construído histórico, os direitos humanos das mulheres não traduzem uma história linear, não compõem uma marcha triunfal, nem tampouco uma causa perdida. Mas refletem, a todo tempo, a história de um combate, mediante processos que abrem e consolidam espaços de luta pela dignidade humana, como invoca, em sua complexidade e dinâmica, o movimento feminista, em sua trajetória plural. (PIOVESAN; PIMENTEL, 2011, p. 101)
\end{abstract}

Refletindo o trabalho de décadas de lutas sociais, tanto no direito internacional quanto interno, a Lei Maria da Penha representa o principal diploma pátrio no combate à violência doméstica e familiar contra a mulher, tomando por base a principiologia advinda do Direito Internacional dos Direitos Humanos (LAVIGNE; PERLINGEIRO, 2011, p. 290), especialmente àqueles oriundos dos tratados internacionais de proteção das mulheres, os quais o Brasil é signatário, como a Convenção para Prevenir, Punir e Erradicar a Violência contra as Mulheres - Convenção de Belém do Pará de 1994 e a Convenção para Eliminar Todas as Formas de Discriminação contra a Mulher, da ONU, 1979 (KATO, 2011, p. 350).

Antes da promulgação da Lei 11.340/2006, havia nomeadamente um conflito de interpretação entre a Convenção de Belém do Pará e a Lei no 9.099/95, Lei dos Juizados Especiais no que tange à violência doméstica pautada no gênero. Enquanto a primeira considera a violência contra a mulher uma violação aos direitos humanos e, portanto, de gravíssima lesividade, os juizados especiais - e suas máximas pela prevalência da conciliação, informalidade e celeridade processual - eram os responsáveis pelo julgamento dos crimes considerados de menor potencial ofensivo, aqueles cujas penas não superem dois anos e, portanto, considerados como crimes de menor potencial ofensivo ou de menor importância. (BARSTED, 2011, p. 27)

É nesse sentido que os crimes de lesão corporal de natureza leve e de ameaça, por exemplo, respectivamente previstos entre os artigos 129 e 147 do Código Penal, eram considerados, nesse contexto anterior à Lei Maria da Penha, crimes de menor potencial ofensivo. Ignorou-se, portanto, toda a complexidade advinda da violência moral, física ou 
psicológica pautada no gênero, reduzindo-a, minimizando-a e, portanto, concorrendo para sua invisibilidade, impunidade e seu consequente crescimento, em um ciclo retroalimentável.

\begin{abstract}
No balanço dos efeitos da aplicação da Lei 9.099/1995 sobre as mulheres, diversos grupos feministas e instituições que atuavam no atendimento a vítimas de violência doméstica constataram uma impunidade que favorecia os agressores. Cerca de $70 \%$ dos casos que chegavam aos juizados especiais tinham como autoras mulheres vítimas de violência doméstica. Além disso, $90 \%$ desses casos terminavam em arquivamento nas audiências de conciliação sem que as mulheres encontrassem uma resposta efetiva do poder público à violência sofrida. Nos poucos casos em que ocorria a punição do agressor, este era geralmente condenado a entregar uma cesta básica a alguma instituição filantrópica. Os juizados especiais, no que pese sua grande contribuição para a agilização de processos criminais, incluíam no mesmo bojo rixas entre motoristas ou vizinhos, discussões sobre cercas ou animais e lesões corporais em mulheres por parte de companheiros ou maridos. Com exceção do homicídio, do abuso sexual e das lesões mais graves, todas as demais formas de violência contra a mulher, obrigatoriamente, eram julgadas nos juizados especiais, onde, devido a seu peculiar ritmo de julgamento, não utilizavam o contraditório, a conversa com a vítima e não ouviam suas necessidades imediatas ou não. (CALAZANS; CORTES, 2011, p. 42)
\end{abstract}

Percebe-se, então, que um dos marcos mais significativos da Lei Maria da Penha e fruto de ampla comemoração pelos movimentos civis que atuaram pela implementação deste diploma legal fora a retirada dos antes denominados crimes de menor potencial ofensivo desta alcunha, estimulando-se a criação dos juizados especializados em violência doméstica e familiar contra a mulher. Esperava-se uma atuação diferenciada da justiça criminal em tais juizados, uma vez que para além das responsabilidades criminais e distribuição das penas, devem-se adotar medidas para enfrentar a violência de gênero em seus efeitos diretos e indiretos contra a autonomia e o exercício de direitos das vítimas (PASINATO, 2011, p. 134).

\begin{abstract}
Em sede de violência doméstica o juiz não pode propor composição de danos ou aplicação imediata de pena não privativa de liberdade (Lei 9.099/95, art. 72). Não há possibilidade de o Ministério Público sugerir transação ou a aplicação imediata de pena restritiva de direito ou multa (Lei 9.099/95, art. 76). Igualmente não é possível a suspensão condicional do processo (Lei 9.099, art. 89). (DIAS, 2007, p. 72)
\end{abstract}

É nesse mesmo sentido que o texto da Lei Maria da Penha é literal em seu artigo 41, afastando qualquer dúvida acerca da inaplicabilidade dos instrumentos da Lei $\mathrm{n}^{\circ}$ 9.099/95 aos casos de violência doméstica e familiar. Há que se questionar, porém, se, mesmo diante do afastamento da conciliação, característica dos juizados especiais, há a impossibilidade de uso dos demais meios consensuais de resolução de conflitos nas demandas referentes à violência doméstica com a intenção explícita de significar a complexidade destes tipos de conflitos para vítimas e agressores, intentando, em última análise, definir maior efetividade às sentenças 
prolatadas, assim como prevenir a reincidência ou aceitação de futuras violências de gênero, cometidas ou sofridas pelas mesmas partes.

Retomando as lições da saudosa professora Ada Pellegrini Grinnover (2009, p. 34), diferentemente da diversidade de instrumentos utilizados como equivalentes jurisdicionais no chamado sistema multiportas, como o utilizado nos Estados Unidos, no Brasil o uso dos métodos consensuais de conflitos pode ser dividido entre a negociação, conciliação e mediação. A primeira é encontrada quando as partes chegam a um consenso sem a necessidade de intervenção de um terceiro, sendo utilizada quando as partes mantém um bom relacionamento e conseguem solucionar a controvérsia de modo objetivo.

Quanto à conciliação e mediação, ambas necessitam de um terceiro facilitador, cuja atividade diferenciar-se-á em conformidade com o método escolhido. Na conciliação, a atividade do referido conciliador dar-se-á pelo incentivo, facilitação ou auxílio para que as partes, que não possuam um relacionamento para além de uma questão superficial, possam se auto-compor. Diferentemente, na mediação, a função do terceiro será mais provocativa, de modo a trazer à tona aspectos do conflito não percebido pelas partes, objetivando-se, portanto, não um acordo, mas o reestabelecimento da possibilidade de um diálogo saudável entre as partes. (GRINNOVER, 2009, p. 3-4)

\footnotetext{
Na mediação, o mediador não interfere na decisão nem induz o acordo, apenas facilita a comunicação entre as partes, permitindo que decidam livremente. Ele deve analisar, em profundidade, o contexto do conflito, permitindo sua ressignificação e, conseqüentemente, novas formas de convivência e prevenção de novos conflitos. Outra diferença fundamental entre a mediação e outro instrumento consiste na presença de um terceiro imparcial, que não opera, em princípio, com base em julgamentos de valor, mas permite, pelo manejo da sua intervenção, que as partes oponentes reflitam e cheguem a encontrar um caminho para a superação do conflito, identificando suas raízes e reorientando atitudes e ações na busca de uma superação. Com isso, pretende-se transcender o "modelo punitivo" para um "modelo de justiça penal diferenciado", pautado no restabelecimento do diálogo, na construção de pactos e acordos diante de interesses divergentes e na ressignificação de contendas, proporcionando a retomada da autodeterminação das pessoas. (NOBRE; BARREIRA, 2008, p. 146)
}

A partir de então, percebe-se que o uso da Mediação pode ser útil frente a conflitos referentes à violência doméstica, de modo a se problematizar sua utilização em concomitância ou separadamente com a técnica da Constelação Familiar Sistêmica.

\section{3- DA POSSIBILIDADE DE USO DA TÉCNICA DA CONSTELAÇÃO FAMILIAR NOS CASOS DE VIOLÊNCIA DOMÉSTICA}


Concebendo-se o uso da Técnica da Constelação Familiar como uma técnica a auxiliar uma compreensão mais ampla dos problemas judicializados, em especial os que permeiam a complexidade das relações familiares, e, principalmente, considerando-se sua utilização precedendo a utilização de qualquer tentativa de resolução consensual de conflitos, como adiantado supra, é necessário, antes, que se discuta a possibilidade de uso de um meio consensual aos casos de violência doméstica, tendo-se o especial cuidado de não propor qualquer alternativa frente a estes casos que contribuam para minimizá-los ou que possam concorrer para a impunidade dos agressores de violência doméstica e ou intrafamiliar de mulheres.

Dispõe a Resolução n ${ }^{\circ} 125$ de 2010 do Conselho Nacional de Justiça em seu artigo $1^{\circ}$ que a Política Judiciária Nacional de tratamento aos conflitos de interesses tem por objetivo a solução dos conflitos pelos meios mais adequados à sua natureza e peculiaridade permitindo-se que se conclua haver franca consideração às especificidades e complexidades das demandas referentes à violência doméstica.

É nítido e justificável o ranço e rechaço, especialmente dos movimentos feministas, às conciliações nas demandas de violência doméstica, uma vez que as diversas vulnerabilidades que mulher vítima deste tipo de violência exibe, não possibilitam que ela atue em igualdade de condições com seu agressor em um contexto de conciliação. No entanto, não há que se negar a importância da mediação para reestabelecimento do diálogo nos conflitos em que o gênero fora a justificativa para a violência (NOBRE; BARREIRA, 2008, p. 149).

\footnotetext{
Quer-se com isso apresentar a viabilidade da mediação, levando em consideração suas limitações, como uma forma facilitadora, para que qualquer tipo de relação que subsista possa ser vivenciada sem violência. Isso porque, nos casais que viveram conflitos violentos, se as partes não forem bem trabalhadas individualmente e na mediação, a cada novo conflito, há uma grande possibilidade de novos episódios de violência. Assim, a partir desse novo plano familiar, construído por ambas as partes, haverá provavelmente prevenção da violência. Lembrando sempre que o acordo não parte de uma tentativa de manter a harmonia do casal, mas buscar o respeito entre as pessoas, independente das relações envolvidas. (RAMOS, 2011, p. 108)
}

Observe-se, então, as ponderações de Maria Teresa Nobre e César Barreira (2008, p.149-152) a respeito de um estudo de caso sobre a implantação de um núcleo experimental de mediação na Delegacia Especial de Atendimento à Mulher - DEAM do Estado de Sergipe. O primeiro ponto a ser considerado é ser incontestável que a intervenção judicial não é suficiente para a inibição da violência doméstica de gênero, vez que o que embasa os atos deste tipo de 
violência são conceitos machistas e sexistas introjetados e naturalizados pelo agressor e vítima, que internalizam como normais e aceitáveis os atos de sujeição, humilhação, controle e posse das mulheres, contra os quais decisões e sentenças de caráter meramente punitivos não são capazes de conter ou coibir.

Faz-se oportuno considerar que a proposta de utilização da mediação frente a crimes de violência doméstica e de gênero não visa impedir ou dificultar a punição dos agressores, mas sim viabilizar maior efetividade às decisões e sentenças prolatadas, trazendo à baila facetas dos conflitos não percebidos por ambos e consequentemente viabilizando a consciência de responsabilização dos agressores e de empoderamento das vítimas.

No ano de 2001 o Governo do Estado de Sergipe, por meio de concurso público realizado para ampliação das delegacias de polícia, acabou por assumir o compromisso de renovação e modificação das práticas policiais. Criou-se, assim, um processo de formação policial diante do projeto de construção de um Centro de Atendimento a Grupos Vulneráveis, integrado pelas delegacias especiais de atendimento à Mulher, a Crianças e Adolescentes e de atendimento a grupos vulneráveis - idosos, homoafetivos, profissionais do sexo, portadores de necessidades especiais e grupos vítimas de discriminações. (NOBRE; BARREIRA, 2008, p. 148)

\footnotetext{
Os serviços prestados pela Delegacia da Mulher, atendendo as demandas das mulheres e desenvolvendo atividades que eram identificadas como "extrapoliciais" pela corporação da Polícia Civil, pela maioria dos policiais lotados na DEAM e pelo movimento feminista, apontavam a necessidade de mudanças das suas práticas ou uma ressignificação do trabalho ali desenvolvido. Assim, a especificidade dos atendimentos às demandas das mulheres e a predominância das ações policiais, ao longo de quase duas décadas, como práticas de renegociação de interesses, conciliação entre as partes e mediação de conflitos, levou o grupo de delegadas, que estava participando do processo de construção do Centro de Atendimento a Grupos Vulneráveis, a propor a instalação de um Núcleo de Mediação de Conflitos no novo complexo policial. (NOBRE; BARREIRA, 2008, p. 148)
}

Com a implantação do referido Núcleo de Mediação de Conflitos na DEAM houve uma transformação no formato desta delegacia, assim como a vinculação da mesma a um complexo policial, o qual não apenas se encontrava no mesmo espaço físico da delegacia, como viu-se submetido a uma coordenação unificada e com setores comuns. Tais mudanças garantiram, segundo depoimentos das delegadas e dos agentes penitenciários da DEAM, melhores condições de trabalho, assim também como um aumento da satisfação e valorização profissional. (NOBRE; BARREIRA, 2008, p. 150) 
Do mesmo modo, ficou evidente no estudo de caso em comento que a ressignificação do trabalho policial, por meio da implantação do Núcleo de Mediação na delegacia especial, trouxe maior visibilidade ao trabalho dos agentes policiais e delegadas, facilitando o acesso da população à DEAM. Não só, o estigma da mulher vítima de violência que registrava a ocorrência e depois a retirava fora superado, através da maior importância dada à qualidade do serviço prestado, com a escuta e acolhida da mulher, observando-se, inclusive, uma redução da reincidência (NOBRE; BARREIRA, 2008, p. 150).

Demonstrou-se o avanço da proposta no estado de Sergipe - indo de encontro às críticas provenientes dos movimentos feministas em relação ao uso de meios alternativos em demandas de violência doméstica - que, superando-se a antiga lógica conciliatória, proveniente dos Juizados Especiais, por meio das mediações trabalhadas na DEAM buscava-se a compreensão do conflito e não a coação da mulher em perdoar o agressor, possibilitando-se à reclamante que se dirigisse diretamente ao cartório para encaminhamento do caso à Justiça, assim como a propositura de reflexão e entendimento do agressor da gravidade de sua conduta, as causas do seu comportamento e a identificação das possibilidades de mudança. (NOBRE; BARREIRA, 2008, p. 150-152)

\footnotetext{
Por último, a mediação de conflitos só se aplica aos casos que envolvem os chamados “direitos disponíveis". Esta, no entanto, está excluída nas seguintes situações: a) quando vislumbrada uma grande desproporção de poder entre as partes, sobretudo de ordem econômica, capaz de inviabilizar a consecução de acordos satisfatórios; b) quando há cronicidade da violência; c) quando o conflito possuir uma importância que supera os atos violentos, ou seja, se a convivência litigiosa é necessária para manter a própria relação afetiva do casal. (NOBRE; BARREIRA, 2008, p. 150-151)
}

É nesse sentido que, mesmo diante da possibilidade de mediação aqui defendida, esta deve levar em conta as especificidades de cada caso concreto, assim também como a vulnerabilidade da mulher agredida e sua vontade, prezando-se sempre não pelo retorno da conjugalidade, mas pela possibilidade de restabelecimento de diálogo entre as partes nos casos em que isso seja necessário - a exemplo das situações em que haja filhos entre agressoragredida.

Desse modo estar-se-á respeitando os ditames da Secretaria Especial de Direitos Humanos (2008, p.4), a qual prevê que a orientação de não mediação a conflitos cuja caracterização é de serem considerados como grave violação aos direitos humanos, tal qual a violência doméstica, uma vez que a proposta defendida é promover uma maior e melhor percepção do agressor e da vítima no que tange à complexidade da vulnerabilidade da vítima 
e de seus filhos nas demandas de violência doméstica judicializadas, favorecendo maior efetividade das decisões e sentenças prolatadas, além de poder haver melhor garantia de prevenção de novos atos de violência.

Considera-se assim que tanto a utilização da Mediação quanto da técnica de Constelação Familiar associada ou isoladamente pode configurar uma ferramenta eficiente para favorecer o manejo de demandas de violência doméstica, de modo a trabalhar os conflitos emergentes no seio da relação de convivência entre agressor-agredida, para além da superfície da tipificação dos crimes levados a juízo.

\section{CONSIDERAÇÕES FINAIS}

A Técnica das Constelações Familiares é pautada em três princípios básicos, também denominados Ordens do Amor. Pertencimento, respeito à hierarquia e necessidade de dar e receber/tomar, devem pautar a harmonia das relações familiares e precisam estar conscientes para os indivíduos membros de um determinado sistema familiar.

Nesse sentido, através da representação é permitido ao constelado, tanto individualmente e com a consequente utilização de bonecos ou demais objetos, como em grupo, ressignificar e compreender como, no sistema familiar ao qual integra, são apresentadas as falhas no uso das Ordens do Amor.

A introdução desta técnica ao Direito Brasileiro deu-se pela implantação de seu uso pelo magistrado Sami Storch junto à Vara de Família da comarca de Castro Alves, interior da Bahia no ano de 2006, como fase preparatória e antecessora às audiências de conciliação ou mediação. Mostrando-se a tentativa exitosa por meio dos resultados obtidos $-91 \%$ de conciliações em audiências em que uma das partes fora à terapia e 100\% de conciliações quando ambas foram consteladas, nos anos de 2013 e 2014 -, a iniciativa expandiu-se pelo território nacional, sendo utilizada constantemente em pelo menos 11 dos estados federados, a exemplo de Alagoas, Pará, São Paulo, Rio Grande do Sul e Amapá.

Percebeu-se, diante das especificidades e complexidades das demandas referentes à violência doméstica que, dentre os meios consensuais de resolução de conflitos - negociação, conciliação e mediação - seria esta última a mais adequada a intentar trabalhar com o problema raiz da violência, vez que o que se buscaria seria a melhor significação do conflito pelas partes a fim de viabilizar o reestabelecimento do diálogo entre elas, em especial quando há a existência 
de filhos entre o ex ou atual casal, em um contex to de conflito de alta complexidade, poder de dano, consequências e sofrimento.

Em contrapartida, percebeu-se que, diante das demandas referentes à violência doméstica, a utilização dos ditos meios consensuais entre agressor e agredida mostra-se desarrazoada em dois pontos. Inicialmente, o uso de conciliações, na prática, impostas, sem qualquer preparo técnico do magistrado ou conciliador para a devida e criteriosa utilização desta técnica, no âmbito dos juizados especiais, regidos pela Lei $n^{\circ}$ 9.099/95, quando da inexistência da Lei Maria da Penha, relegava a gravidade dos crimes de violência pautados no gênero - e concebidos como violação aos direitos humanos desde a Convenção de Belém do Pará - a crimes de menor potencial ofensivo e, portanto, transacionáveis. Do mesmo modo, ainda nesse ponto, a inexistência de um diploma legal que protegesse a mulher diante da situação de vulnerabilidade expressada pela violência doméstica, a impelia a conciliar com o agressor, inclusive pela pressão social de continuidade da família e receio de perda de guarda dos filhos ou de lesão patrimonial.

Um segundo ponto a ser observado, já sob o manto da Lei Maria da Penha, é que a Secretaria Especial de Direitos Humanos dispõe que violações a direitos humanos não são mediáveis - constituindo a violência doméstica um deles.

Ocorre que, como demonstra a experiência da implantação do Núcleo Experimental de Mediação na Delegacia Especial de Atendimento à Mulher - DEAM de Sergipe, o reestabelecimento do diálogo entre as partes de um litígio de violência doméstica, especialmente quando há vínculos indissolúveis entre ambos, como a existência de filhos, permite que essa demanda e as demais, que transcorram nas varas de família, possam ser resolvidas de modo menos desgastante e mais eficaz para ambas as partes e para seus filhos.

Assim sendo, o que se buscaria com a mediação frente à violência doméstica e ou intrafamiliar de gênero não seria a reconciliação do casal, mas sim a compreensão da gravidade, complexidade e naturalização das agressões sofridas pela mulher vítima e a oportunização para que tanto a vítima quanto o agressor possam melhor compreender o fenômeno da violência doméstica no qual se encontram imersos, e assim, haver maior possibilidade de efetividade tanto das decisões e ou sentenças proferidas no curso das ações judicializadas nestes tipos de demanda, quanto das decisões e sentenças prolatadas nas demanda de Família, envolvendo as mesmas partes, logo, os mesmos filhos, que frequentemente tramitam simultaneamente.

Devendo-se analisar a pertinência da mediação a cada caso concreto, acredita-se adicionalmente que o uso da Técnica das Constelações Familiares nos casos de violência 
doméstica e de gênero pode se mostrar consentâneo não apenas com as previsões da Portaria n 125 de 2010 do CNJ - que prevê o estímulo do Poder Judiciário a formas mais adequadas à resolução de conflitos levados ao Estado-juiz -, como também e, primordialmente, à maior eficácia do enfrentamento do problema raiz que levara as partes a buscarem as instituições do Sistema de Justiça.

É neste contexto de alta complexidade e gravidade que caracteriza a ocorrência da violência doméstica ou familiar de gênero que se deve considerar a possibilidade de uso da referida técnica também às demandas de violência doméstica, especialmente quando houverem vínculos de parentalidade entre as partes, possibilitando até que o agressor ressignifique, por meio da representação, os conceitos patriarcais por ele introjetados como fatores etiológicos e de risco para a prática da violência contra a mulher em todas as suas modalidades.

\section{REFERÊNCIAS}

ALMEIDA, José Carlos Dias de. Constelação Familiar Sistêmica, 2008. Disponível em: < htp://henriquefernandes.com.br/ARTIGO\%2520CONSTELA\%25C3\%2587\%25C3\%2520CA RLOS.pd > Acesso em: 17 de jul. de 2017.

BARSTED, Leila Linhares. Lei Maria da Penha: uma experiência bem sucedida de advogacy feminita. In: CAMPOS, Carmen Hein de. Lei Maria da Penha comentada em uma perspectiva jurídico-feminista. Rio de Janeiro: Lumen Juris, 2011, p. 13-37.

CALAZANS, Myllena; CORTES, Iáris. O processo de criação, aprovação e implementação da Lei Maria da Penha. In: CAMPOS, Carmen Hein de. Lei Maria da Penha comentada em uma perspectiva jurídico-feminista. Rio de Janeiro: Lumen Juris, 2011, p. 39-64.

CARVALHO, Elza Vicente. Constelações Familiares Sistêmicas. Revista Saúde Quântica, vol.1, n.1, 2012, p. 43-45.

CÉSPEDES, Adele Speck Rendón. A Constelação Familiar aplicada ao Direito Brasileiro a partir da Lei de Mediação. Monografa apresentada ao curso de Direito da Universidade Federal de Santa Catarina, Florianópolis, 2017.

CHIQUETTI, Taciana; CRUZ, Carlos Henrique Souza. As Constelações Sistêmicas Familiares na Justiça do RN: uma interface entre a Psicologia e o Direito, 2016. 
CNJ. Constelação Familiar ajuda a humanizar práticas de conciliação no judiciário. 2016. Disponível em: < http://www.cnj.jus.br/noticias/cnj/83766-constelacao-familiar-ajudahumanizar-praticas-de-conciliacao-no-judiciario-2 >. Acesso em: 19 de jul. de 2017.

CNJ. Juiz consegue $100 \%$ de acordos usando técnica alemã antes das sessões de conciliação. 2014. Disponível em: < http://www.cnj.jus.br/noticias/cnj/62242-juiz-consegue-100-deacordos-usando-tecnica-alema-antes-das-sessoes-de-conciliacao >. Acesso em: 15 de jul. de 2017.

DIAS, Maria Berenice. A Lei Maria da Penha na Justiça: a efetividade da Lei 11.340/2006 de combate à violência doméstica e familiar contra a mulher. São Paulo: Ed. Revista dos Tribunais, 2007.

FONSECA, Cristiane Silva Marques da; SAUAIA, Artenira da Silva e Silva. Defensor Público: agente mediador de conflitos em prol da pacificação social de adolescentes em conflito com a lei. In: CHAI, Cássius Guimarães (org.); BAHIA, Alexandre Gustavo de Melo Franco et al. (coord.). Mediação familiar, infância, idoso e gênero. Rio de Janeiro: Global Mediation, 2014, p. 150-163.

GRINNOVER, Ada Pellegrini. O minissistema brasileiro de Justiça consensual: compatibilidades e incompatibilidades, In: CARMONA, Carlos Alberto. Arbitragem e processo, 3 ed., rev. e ampl., São Paulo: Atlas, 2009, p. 1-30

HELLINGER, Bert. Simetria oculta do amor. Trad. Newton A. Queiroz. 6ed. São Paulo: Cultrix, 2015.

KATO, Shelma Lombardi de. Da equipe multidisciplinar - Artigos 29 a 32. In: CAMPOS, Carmen Hein de. Lei Maria da Penha comentada em uma perspectiva jurídico-feminista. Rio de Janeiro: Lumen Juris, 2011, p. 347-355.

LAVIGNE, Rosane M. Reis; PERLINGEIRO, Cecília. Das Medidas Protetivas de Urgência Artigos 18 a 21. In: CAMPOS, Carmen Hein de. Lei Maria da Penha comentada em uma perspectiva jurídico-feminista. Rio de Janeiro: Lumen Juris, 2011, p. 289-305. 
MUSZKAT, Malvina Ester (org.). Mediação de Conflitos: Pacificando e prevenindo a violência. São Paulo: Summus Editorial, 2003.

NOBRE, Maria Teresa; BARREIRA, César. Controle Social e Mediação de Conflitos: as delegacias da mulher e a violência doméstica. Revista Sociologias, ano 10, n. 20, jul.-dez. 2008, p. 138-163.

PASINATO, Wânia. Avanços e Obstáculos na implementação da Lei 11.40/2006. 2011.

PIOVESAN, Flávia; PIMENTEL, Silvia. A Lei Maria da Penha na perspectiva da responsabilidade internacional do Brasil. In: CAMPOS, Carmen Hein de. Lei Maria da Penha comentada em uma perspectiva jurídico-feminista. Rio de Janeiro: Lumen Juris, 2011, p. 101-118. 